This is a post-peer-review, pre-copy edited version of an article published in Drug and Alcohol Review. The definitive publisher-authenticated version of

The global economic burden of alcohol: a review and some suggestions (Baumberg 2006). Drug and Alcohol Review, 25(6):537-552.

is available online at http://informahealthcare.com/doi/abs/10.1080/09595230600944479 


\title{
The global economic burden of alcohol: a review and some suggestions
}

\author{
Ben Baumberg ${ }^{1}$ \\ ${ }^{1}$ Institute of Alcohol Studies, London, UK
}

\begin{abstract}
Background: economic arguments for acting for health are increasingly important for policymakers, yet to date there has been no consideration of the likely economic burden of alcohol on the global level. Method: a review of existing cost estimates was conducted, with each study disaggregated into different cost areas and the methodology of each element evaluated. The range of figures produced from more robust studies was then tentatively applied on the global level. Results: the reviewed studies suggested a range of estimates of 1.3-3.3\% of total health costs, $6.4-14.4 \%$ of total public order and safety costs, 0.3-1.4\% of GDP for criminal damage costs, 1.0-1.7\% of GDP for drinkdriving costs, and 2.7-10.9\% of GDP for workplace costs (absenteeism, unemployment and premature mortality). On a global level, this suggests costs in the range of $\$ 210$ $\$ 665$ bn in 2002. Discussion: these figures cannot be understood without simultaneously considering six key problems: (i) the methods used by each study; (ii) who pays these costs; (iii) the 'economic benefits' of premature deaths; (iv) establishing causality; (v) omitted costs; and (vi) the applicability of developed country estimates to developing countries. Conclusion: alcohol exerts a considerable economic burden worldwide, although the exact level of this burden is a matter of debate and further research. Policymakers should consider economic issues alongside evidence of the costeffectiveness of particular policy options in improving health, such as in the WHO's CHOICE project.
\end{abstract}




\section{Introduction}

However much those working in the public health field may prefer otherwise, the importance of 'economic' arguments ${ }^{1}$ when trying to persuade policymakers to act for health cannot be understated. As Markos Kyprianou, the Commissioner for Health and Social Protection in the European Commission, has recently put it, "this evidence provides a powerful argument for European governments to invest in the health of their populations, not only because better health is a desirable objective in its own right, but also because it is an important determinant of economic growth and competitiveness" $(1: 5)$.

This is no less true in the alcohol field than in any other field of public health. The recent resolution on alcohol in the World Health Assembly noted that WHO members are "concerned about the economic loss to society resulting from harmful alcohol consumption" (WHA 58.26). Single figure estimates are also useful for comparing the size of different health issues, often tobacco, alcohol and illicit drugs (2), and are a platform on which to build economic analyses of particular policy options (see Chisholm et al, this issue). Finally, the data demands in these analyses acts as a spur to filling gaps in the evidence base (3), in particular for the costs omitted in cost-effectiveness analyses (a point to which we will return in the conclusion).

Unsurprisingly then, there are numerous social cost estimates for different social issues at the European level (4-6). Amongst these are a series of estimates of the social cost of alcohol in Europe, originally within the European Alcohol Action Plan 2000-5 (see also $7)$, but also two increasingly sophisticated aggregate level estimates $(8,9)$, culminating in a WHO decision to initiate a detailed study of the social cost of alcohol in each of the countries of Europe.

\footnotetext{
1 'Economic' is here narrowly defined as arguments involving the money economy, rather than the broader sense that encompasses changes in Quality of Life (which is therefore much closer to a public health approach); this point is developed below in footnote 21 .
} 
However, to date there have been no estimates of the likely economic burden at the global level. This paper attempts to fill this gap by using a review of existing social cost studies - conducted for the most recent European estimate - to tentatively outline the international economic burden due to alcohol. As well bringing previous reviews up-todate, this review also disaggregates existing studies to look at individual cost areas, which gives a much clearer picture of how estimates compare to each other.

At the same time, though, the review also highlights the assumptions on which these estimates are based, many of which appear both problematic in themselves and are misinterpreted by policymakers in practice. Furthermore, virtually all of these studies have been conducted within developed countries, and neither the exact estimates nor the assumptions within them may be appropriate in developing countries. The paper therefore goes on to critically review the estimates of economic burden, focusing on five key problems that need to be addressed. The paper concludes with some suggestions as to the likely size of the global economic burden due to alcohol, and finally places these estimates within the wider context of economic evaluations.

\section{Methods $^{2}$}

\section{Theoretical background}

The point of departure for nearly all social cost studies is an unreal 'what if?' question 'what if alcohol disappeared from the world today?' Behind this unreal scenario lies an even bigger assumption - that in this hypothetical world, all of the spending and time spent drinking alcohol is redirected to something that does not burden society in any way. Thankfully the utility of these studies does not depend upon the plausibility of this situation, with this imaginative thinking instead being a way of creating a summary measure of how much (and in what areas) alcohol burdens human society materially.

\footnotetext{
${ }^{2}$ A number of methodological considerations are not discussed here for both readability and space. However, readers with unanswered questions should refer to Anderson and Baumberg (2006) or contact the present author.
} 
Social cost studies also involve a number of other assumptions, some shared between all studies and others varying between them, of which it is beyond the scope of this article to cover in full. ${ }^{3}$ It is however worth being aware that these studies generally estimate the economic burden of all past and current drinking on a particular year (prevalence-based), rather than the burden of new alcohol-related problems on all future years (incidencebased).

The review also divides between 'tangible' and 'intangible' costs (see Table 1). 'Tangible' costs are those costs that are already in monetary form, such as spending on healthcare (direct costs), or production losses (indirect costs). 'Intangible' costs are those that do not exist in a monetary form, such as pain, suffering or loss of life itself. The question of whether intangible costs count as an 'economic cost' is discussed below in footnote 21, and their importance for understanding economic contributions to alcohol policy is discussed in the conclusion.

\section{Finding and selecting source studies}

This paper is based on a review of costing studies undertaken since 1990 (earlier studies are generally weaker and have been reviewed elsewhere (10)). An initial list of studies was obtained from PubMed, ETOH and the Web of Science, checked against the WHO's Global Status Report on Alcohol 2004 (11) and a search of the Internet through google.com. ${ }^{4}$ These were supplemented by studies from four previous reviews (10),(1214) as well as those provided by the European Alcohol Policy Network (APN; www.eurocare.org/btg/). ${ }^{5}$ These studies were selected if they included a new estimate of the social cost in at least one cost area (the full list of studies included is shown in Table

\footnotetext{
${ }^{3}$ Interested readers can also find further discussion elsewhere (56).(17, 28, 106)

${ }^{4}$ The following search terms were used: alcohol*, combined with economic*, cost*, or burden*.

${ }^{5}$ Data in languages other than English, French, German or Spanish were translated by the relevant APN member, using a standard form to extract relevant information only. In two cases the studies were not publicly available; for transparency purposes, the English summaries have been made available on the APN website.
} 
1). Due to data limitations, it was not possible to include studies for either West Germany (e.g. 15) or sub-national regions $(13,16)$.

\section{Method of analysis}

To overcome problems of methodological inconsistency and coverage of different cost areas, each study was divided into separate cost areas. ${ }^{6}$ For each one, costs were then expressed as the percentage of an appropriate common metric (or GDP if none were available) - healthcare costs, for example, were expressed as a percentage of total healthcare expenditure. The methods used in different studies were also compared using a checklist of methods and transparency, based as far as possible on the WHO Guidelines for Estimating the Costs of Substance Abuse (17) and shown in Tables 2-5.

[Tables 2-7 from about here]

\section{Results}

The results of the review are shown in Tables 2-7. Each table presents the results for a particular cost area, expressed as a share of a common metric ('total health costs' for health, 'total public and order and safety costs' for crime, but GDP in all other cases). The tables also include additional information on the method used by the authors in producing the estimate, with studies meeting all of these criteria shown in bold. This review is therefore 'systematic' in the sense that it examines a common set of methodological criteria within each cost area - but it is also 'opportunistic' in the choice of these criteria, which are only partially based on good practice guidelines (e.g. 17) and partially based on the limited extent of the information given in the studies.

It should be noted that there is still substantial methodological variation between studies that appear similar in the tables, to the extent that it is impossible to attribute variations in

\footnotetext{
${ }^{6}$ All transfers between individuals - whether deliberate or stolen - were also removed $(17,107)$, as have the health costs of violent crime (due to the risk of double-counting (28)) and non-market costs such as household work (as these cannot strictly be compared to GDP (17)).
} 
costs to genuine differences in levels of harm. For example, differences in health costs may reflect the use of different estimates of relative risk for the same condition, while differences in premature mortality costs may reflect the use of different assumptions as to future productivity increases (even the linked studies from Canada use assumptions on productivity growth that differ by $2 \%$ ).

\section{A global estimate}

While the figures presented in Tables 1-7 are interesting for the purposes of comparison, the easiest way to comprehend what these figures mean is to apply them globally, based on the common metric used in the review. ${ }^{7}$ Clearly this will be a tentative estimate subject to several qualifications, which are covered in detail in the discussion section of this paper. Nevertheless, presenting these implied figures from the review gives a first crude indication of the likely global economic burden of alcohol, representing both information in itself for policymakers and a platform for future work.

The most sensible basis for a global estimate is to restrict the estimates to results from the best studies, i.e. those highlighted in bold in Tables 2-7. If these are applied on a global basis, then we can estimate that the global economic burden of alcohol is between \$210bn and \$650bn in 2002. ${ }^{8}$ This is made up of \$40-105bn for health, \$55-210bn for premature mortality, \$30-65bn for absenteeism, \$0-80bn for unemployment, \$30-85bn for criminal justice systems (police, prisons, courts) and $\$ 15-50 \mathrm{bn}$ for criminal damage. This is equivalent to $0.6-2.0 \%$ of global GDP (for the countries included) - or more simply, somewhere between the total GDP of Austria and India.

One small refinement can be made to these extremely crude figures, by using the existing estimates of the global health burden caused by alcohol (see Rehm, this volume). If we

\footnotetext{
${ }^{7}$ Crime costs are expressed as a \% of GDP given the lack of available data on 'public order and safety' expenditure as presented in Table 6.

${ }^{8}$ GDP figures taken from the UN Statistical Division 1/2/2006; health spending as \% of GDP figures taken from the World Health Report 2005, published by the WHO. All figures are stated to the nearest $\$ 5$ bn to avoid giving a misleading imprecision of precision.
} 
adjust for the difference in health burden between the countries where cost studies have been conducted (all very low child and adult mortality) and other countries worldwide, then the estimate for the global burden of alcohol on health costs becomes $\$ 50-120 \mathrm{bn}$ (compared to \$40-105bn for the initial method above). The WHO figures further suggest that developed countries may have a slightly higher share of homicides and road traffic deaths due to alcohol than elsewhere. ${ }^{9}$

\section{Discussion}

While this review allows a tentative first estimate of the global economic burden of alcohol, it cannot be understood without considering six further points that are discussed below in turn: (i) the methods used by each study; (ii) who pays these costs; (iii) the 'economic benefits' of premature deaths; (iv) establishing causality; (v) omitted costs; and (vi) the applicability of developed-country estimates to developing countries.

\section{The methods used by each study}

The present estimate is a distinct improvement on previous review-based estimates $(7,8)$ as it accounts for the different cost types included in different studies, and examines how robust the methods are within each cost type and within each study. Nevertheless, there are substantial outstanding concerns as to the accuracy of individual studies, as data limitations are often only surmountable through extrapolations from other data sources (for example, assuming that the alcohol-attributable share of outpatient health costs is equal to that of inpatient health costs). Epidemiological data may be similarly extrapolated from one country to another and from mortality to morbidity. Such extrapolations may be an inevitability in social cost studies given their onerous data demands, but it does mean that no estimate can be seen to be precise.

\footnotetext{
${ }^{9}$ For homicide: 31 (developed countries) vs. 32\% (developing) of deaths for males and $31 \%$ vs. $22 \%$ for females. For road traffic accidents: $41 \%$ of deaths in men aged 15-29 compared to $30 \%$ in other regions. 'Developed countries' defined as countries with very low child and adult mortality; 'developing countries' refers to all other countries. Average figures are obtained by scaling the reported alcohol-attributable fraction for homicide (Rehm et al 2004) by the numbers of homicides in each region (see http://www.who.int/healthinfo/bod/en/index.html)
} 
A more theoretical concern is that the review can only follow the data and assumptions used by primary researchers, the most contentious of which relates to the method of placing a value on premature death. Studies most commonly assume full employment, where prematurely deceased workers are not replaced by those who are unemployed. However, even by the late-1990s it had been widely noted that this could lead to a large over-estimation of costs, and alternative methods were being recommended (18).

The most common of these - known as the 'friction cost' method - has been to assume that workers who die are replaced at work by a previously unemployed person (19), which produces a much lower cost of alcohol to society $(20,21)$. This in turn has been critiqued for being over-sensitive to macroeconomic variables that are difficult to predict (22), and more importantly for making unwarranted assumptions that lead to the friction cost method being an underestimate (see 23, 24). For example, the 'friction cost' generally misses the cost of people who cannot be replaced by currently unemployed people and the likely chains of vacancies that arise by replacing workers with people employed elsewhere, as well as the cost of training up new workers $(23,25)$. In practice, then, the 'true cost' is likely to lie between the two estimates - but it is difficult to be more precise as to exactly where the cost lies.

\section{Who pays these costs?}

Perhaps more important than the level of costs per se is whether it is drinkers, other individuals, government or businesses that pay them. Politicians often see external costs - those that the drinker imposes on other people, such as taxpayer-funded healthcare costs in the UK - as a reason to intervene in markets, as people do not (often) take these into account themselves. On the other hand, private costs - those that are paid by the drinker or their family, such as private healthcare in the US - may be seen as a matter of individual choice, given that rational individuals only do something if the (private) gains are more than the (private) costs (26).

As well as this basic division of costs, there are situations that are 'private' in a simple view but may nevertheless be persuasive in justifying government regulation. One of 
these is harm within the household (e.g. child neglect), which is treated as private in mainstream economics but often seen as requiring intervention in wider society. Indeed, it seems clear that due to alcohol-related harm within the family, the proper unit of analysis should be the individual rather than the household.

Another politically important situation is where people cannot make rational decisions, such as where they are addicted, or if they do not have good information on the costs and benefits of how much they drink $(17,27)$. Some researchers have argued that private decisions made in these conditions should also be included in the total social cost figure typically by putting a certain share of total consumption as 'abusive' $(28,29)$. Clearly this decision adds substantial amounts to the total figure - the total estimated social cost of alcohol in the EU of $€ 125$ bn (9) compares to $€ 125$ bn spent on beer alone in the EU (30), which using the assumptions of Collins and Lapsley in Australia ${ }^{10}$ would imply an additional cost of $€ 25 \mathrm{bn}$. One consequence of including these costs, however, is that a poor information campaign - which would increase knowledge of the risks of alcohol without changing behaviour - would substantially reduce costs without affecting harm, which would seem to be a slightly counterproductive result of an ineffective policy.

Studies that look only at external costs are rare, and are generally adjustments to existing major social cost estimates (31-33). These suffer from the exclusion of 'transfer costs' in most studies - where money is moved from one group to another (e.g. from government to the unemployed), rather than being lost - which are likely to be significant in external cost studies. The most revealing study that looks at who pays the costs comes from Australia (28), where the highest costs for business and government were workforce labour, road accidents and crime. ${ }^{11}$ Together these accounted for nearly two-thirds of the total cost, even after considering the enormous private cost of 'resources used in abusive

\footnotetext{
${ }^{10}$ This assumption is that $20 \%$ of all alcohol consumed was drunk by addicted drinkers and should therefore be included in the social cost. This excludes the cost of drinking when the drinker does not have complete information on the risks of alcohol.

${ }^{11}$ It should be noted that health costs in the Collins and Lapsley studies are relatively low compared to other studies as they take into account the 'savings' of premature deaths; see below.
} 
consumption'. Other research also suggests that only around one-half of those injured in these accidents are the drink-drivers themselves (9), which means that much of the cost is borne by the 'innocent victims' of these accidents.

\section{The 'economic benefits' of premature deaths}

One of the stranger aspects of social cost studies is that they tend to look at present costs without looking at future savings. For example, in a world without alcohol, a person dying of alcohol-attributable liver cirrhosis at age 50 may otherwise have contracted Alzheimer's disease at age 80. This may partly explain the inconsistent and otherwise puzzling finding (34) that healthcare costs for abstainers and heavy drinkers are both much higher than for lighter drinkers (e.g. 35), although this may also reflect methodological weaknesses (36) and relatively short follow-ups. ${ }^{12}$.

The 'real' health burden therefore depends on whether alcohol-related disease is cheaper to treat than all the diseases that people would otherwise have got in an alcohol-free world. This means that there is a lower social cost of conditions that kill people quickly, as opposed to conditions that lead to long periods of illness requiring expensive treatment (37). In the one study that has investigated this for alcohol, an overall healthcare cost was found, but this was a much lower value than found in the conventional methodology. 13

Does this mean that conventional health cost estimates should be discarded as meaningless? I would argue that this would be an overreaction, for two reasons. Firstly,

\footnotetext{
${ }^{12}$ More theoretically though, there are two reasons why we may not expect individual-level studies to match the social cost results. Firstly, there may well be systematic biases in how individuals react to healthcare, with some research suggesting that relatively heavy drinkers may have shorter stays in hospital as they cannot carry on with their drinking (36). Such biases are particularly important for outpatient service use, where variations in care-seeking behaviour are likely to explain at least part of the negative relationship between alcohol use and outpatient service utilization (see summary in 35).

${ }^{13}$ Ironically, Collins and Lapsley also found that the health benefits of alcohol increase the total healthcare burden. This is presumably because cardiovascular disease leads to death relatively more than long-term disability, and so preventing cardiovascular disease leads to an increase in health costs.
} 
cost studies for all social issues use the same methodology, so that any change must be made across the board rather than in a single study. Secondly, these estimates are still meaningful, in that it is accurate to say that an estimated \$50-120bn was spent treating conditions caused by alcohol in 2002. It is unarguable, however, that the figures should be presented clearly to avoid the all-too-common misunderstandings among policymakers.

It should finally be noted that a parallel finding can be found for the productivity cost of premature death, if we take into account the resources that people would otherwise have used up if they had stayed alive (e.g. pensions). Two studies have estimated this for alcohol, in both cases finding that it reduced the cost of premature mortality by about $30 \%(28,38)$. However, the implication of these analyses is that an individual's expected production is less than their expected consumption from the age of 55 (39), which is politically troubling, and whose implications are discussed in more detail in the conclusion.

\section{Establishing causality}

The difficulty in dividing between what is due to alcohol from what is merely associated with it is a common one in research on alcohol, and there is clearly insufficient space to discuss the issue fully in this paper (for an introduction, see the brief review in 40). It is nevertheless essential to consider the issue of causality in social cost studies, if only because it is often brushed over in both the studies themselves and previous reviews. The most illuminating way of showing these points briefly is to look at a single case study, that of lowered productivity.

While there is agreement between drinkers (41) and employers (42) that drinking can lead to lowered productivity at the workplace, there are substantial difficulties in valuing this precisely. Most of the existing effort has been made by economists looking at the issue of wages and alcohol, based on the assumption that - in a perfect labour market lower productivity or attendance due to alcohol will result in lower wages. Such assumptions underlie estimates in several countries (e.g. 21, 43, 44), although several of 
these (45) simply imported a US estimate (46) into their own country due to a lack of other data. ${ }^{14}$ Yet while this US study looked at the wage penalty in people who have suffered from alcohol dependence, nearly all studies also show that light drinkers have higher wages than abstainers (Russia in 47, the US in 48, Australia in 49, the Netherlands in 50).

The key question here, then, is whether these results show 'genuine' costs and benefits of alcohol, or simply reflect systematic biases in the methods used (51 p360).

Firstly, income could influence alcohol consumption, in that people with more money can buy more alcohol. Some researchers have claimed that looking only at alcohol use disorders (rather than consumption levels) reduces this bias, because individuals do not 'choose' to suffer from these in the same way that they can choose to change how much they drink (46). ${ }^{15}$ Secondly though, and more problematically, both drinking levels and wages may be jointly influenced by some other factor, such as how much risk someone is willing to take in their decisions. There has been a tendency to ignore this problem, however, presumably because the spurious relationship will be in the 'right' direction and therefore allow a cost burden to be estimated.

These problems are relatively common in economic analyses, and economists have developed complex tools to deal with them. ${ }^{16}$ Yet the unavoidable conclusion from this

\footnotetext{
${ }^{14}$ Even this US evidence is not altogether convincing - a wage penalty was only found for men who had ever suffered from alcohol dependence (but not alcohol abuse, and not for women at all). The estimate also assumes that education is a mechanism through which ever-being alcohol dependent can affect wages (i.e. it uses a reduced-form model). Harwood et al justify this using research that suggests those reporting youthful alcohol abuse have less education than would be expected from their background, although more recent research contradicts this (108). If this assumption is dropped, then Harwood et al find no significant effect in any group.

${ }^{15}$ Although the risk of suffering from an alcohol abuse disorder increases at higher levels (and more detrimental patterns) of consumption, there are more intervening variables (such as genetic vulnerability) that create a more uncertain probability than found for the level of consumption.

${ }^{16}$ Many studies use called an 'instrumental variables' technique by looking at the association between wages and variables that are correlated with alcohol use but not with wages (e.g. alcohol tax changes).
} 
research is that these tools are simply not good enough to produce unbiased estimates of the effect of alcohol. For a start, the estimates from this method are often implausibly large (50), to the extent that the National Bureau of Economic Research concluded that "it is unlikely that previous studies... have produced credible estimates of the effect of alcohol use on labor market outcomes" (51:370). A more recent study documents these flaws even more convincingly by looking at the same people over several years, thereby controlling for all the differences between drinkers and non-drinkers that do not change over time (52). This found no significant effect of alcohol use at the $5 \%$ level on wages in either men or women, for any level of consumption or for binge-drinking.

Does this mean that there is no relationship between alcohol use and productivity or absenteeism (51)? ${ }^{17}$ While some researchers would seemingly answer yes (53), it is unclear on further reflection why anyone ever expected wages to have a 'genuine' relationship with levels of alcohol use. At a basic level, worker productivity may not be easily visible to an employer, and even if it is visible then wages may take some time to reflect changes in productivity (21). More importantly, in a workplace culture where drinking is accepted, there may even be a workplace penalty where drinking is expected, such as for the cantineras in Texas who see drinking as a workplace duty (54). Nondrinking could equally damage prospects where intra- and inter-firm networking is based on socialising over drinks, as suggested by the $£ 250$ per employee spent on alcohol by UK advertising firms (55).

This case study provides two lessons for future research. Researchers should be careful in using a proxy variable instead of the measure they are actually interesting in, but more importantly, the ever-present risk of spurious relationships requires imagination in research design rather analysis - a point that echoes a call made 15 years ago $(27,56)$. Other than better use of natural experiments, an interesting example is a small US study that looked at the same individuals over four weeks, and found that the relative risk of

\footnotetext{
${ }^{17}$ Similar results have also been found for drinking and unemployment, in that alcohol use disorders are associated with higher unemployment, light alcohol consumption is sometimes associated with lower unemployment, and complex methods often produce implausible results (51).
} 
being absent was 10-times greater for individuals on the day after drinking. Although this study had other methodological weaknesses, ${ }^{18}$ it demonstrates how creative approaches can produce more persuasive results than more expensive and sophisticated number-crunching.

\section{Omitted costs}

Alcohol touches upon many areas of human life, and few studies can claim to covert these comprehensively. This may be unimportant, however, if the omitted costs are merely those that are likely to be relatively insignificant. For example, the cost of fires that occur because people are drunk is only $1 \%$ of the total cost in all of the four countries where this has been estimated $(21,45,46,57)$. It is therefore unfortunate that many of the frequently omitted cost areas fall into the groups of either 'miscellaneous productivity costs' or 'other crime costs', which are both likely to be responsible for a substantial burden.

'Miscellaneous productivity losses' includes many areas where the effect of alcohol is costed but the impact on people's ability to work is ignored. For example, the labour loss due to all workplace accidents accounts for most of the estimated $€ 55 \mathrm{bn}$ total cost for the EU15 (6). Other parallel areas include lost working time from travel delays due to drinkdriving accidents $(58,59)$, and from people imprisoned due to alcohol-attributable crime $(28,46,57)$ as well as their victims $(42,60)$. More fundamentally, traditional methods systematically miss out the work done by people outside the labour force, such as caring, housework and voluntary work (see Table 3). More recent studies find ways of giving a value to this work, generally finding that it significantly adds to the total burden of alcohol $(21,38,46,61)$.

\footnotetext{
${ }^{18}$ For example, alcohol consumption was reported retrospectively at two-week intervals, and the study did not ask about the quantity of alcohol consumed (or any other features) of the drinking occasion. Such weaknesses were enough for a systematic review to classify the study as of 'low quality', although it should be noted that only one study worldwide met their definition of even 'medium quality' (109).
} 
Most of the crime costs' considered above concentrate only on the cost of crime in terms of the criminal justice system, and occasionally also look at the value of criminal damage. However, the study from the UK Prime Minister's Strategy Unit was able to build upon an existing estimate of the 'cost of crime' to look at the money spent by private citizens and companies on preventing crime in advance (burglar alarms, security guards). This added up to a burden that was equivalent to the total value of criminal damage and only slightly lower than the cost of police, courts and prisons, demonstrating that the omission of these costs leads to a serious underestimate of the cost of alcohol-attributable crime $(42) .{ }^{19}$

From a global perspective, though, perhaps the most worrying omission is one that has never been included in a social cost study - the burden of sexually transmitted diseases (STDs), particularly the enormous burden of HIV/AIDS (62). Certainly there is almost universal evidence that alcohol is associated with risky sex (e.g. unprotected sex, multiple sex worker partners) (e.g. 63, 64), which is in turn a risk factor for STDs (65-69). As discussed at length above, though, the difficulty lies in teasing out the causal link from a multitude of simple associational data. On the one hand, there are clear theoretical reasons for seeing this link as 'genuine', given the pathways through which drinkers themselves suggest alcohol genuinely affects sexual risk taking, including reduced inhibitions and providing a socially acceptable excuse for not using condoms $(70,71)$. This is bolstered by experimental evidence that shows how judgement and risk-taking are affected by drinking in a laboratory setting (72).

On the other hand, there has been a greater problem in demonstrating a link between risky drinking and actual STD outcomes. A recent systematic review looking at STDs (but excluding HIV/AIDS) found that there are substantial problems in saying confidently that there is a causal role of problem drinking (73). Studies looking at the dose-response relationship have found inconsistent results, and insufficient effort has

\footnotetext{
${ }^{19}$ The same study also valued stolen property as a cost to society, but this has been removed from the current comparison as it was felt to count as a 'transfer' rather than a 'loss'.
} 
been given to ruling out alternative explanations of an association. Moreover - and despite the claims of Cook and Clark - the association between problem drinking and STDs in these studies is simply inconsistent. ${ }^{20}$ In contrast, though, a recent National Bureau of Economic Research paper found that higher alcohol taxes were associated with lower gonorrhoea rates among young adults in the US, although the results for HIV rates are less clear (74).

Overall, the implication for future economic studies is that more attention should be paid to STDs, particularly where the economic burden of HIV/AIDS is high. Despite the need for further research, there is at least as much evidence for a relationship between STDs and alcohol use as there is for lowered productivity at the workplace, and the NIAAA in the US has concluded that "decreasing alcohol use in people who have HIV or who are at risk for becoming infected reduces the spread of HIV and the diseases associated with it” (75). Even if the causal relationship is much less than the associational one - such as for condom use, where a recent meta-analysis suggested that drinking may only be important for condom use at first intercourse (76) - this may still lead to a considerable cost, especially considering the effect this may have on long-term equilibrium points.

\section{Are the costs applicable in developing countries?}

Perhaps the most difficult question to answer is whether the costs identified in the countries in Table 1 will be equally applicable in developing countries, as persuasive cases can be made for both higher and lower costs being likely. Lower costs may arise due to limited Government spending on e.g. health systems or crime, or a greater number of potentially employable people to replace those dying or becoming unemployed due to the effects of alcohol. It can also be argued that "where the God of Productivity has few

\footnotetext{
${ }^{20}$ Cook and Clark argue that "problem drinking is clearly associated with an increased risk of STDs" (73 p159), given that 8 of 11 studies found a significantly increased risk of at least 1 STD among problem drinkers compared to non-drinkers. However, this conceals the fact that many studies performed multiple tests separately (e.g. for men and women, for different measure of alcohol use, or for different STDs) - if we instead look across the full 22 contrasts among problem drinkers, we find that over half were nonsignificant, and that 2 further contrasts were insignificant in multivariate analyses.
} 
followers, the negative impact of alcohol on production will not be perceived as a problem" (77 p103).

Conversely, additional burdens on health systems in developing countries may not be able to be absorbed in increased spending, and may instead lead to otherwise preventable deaths. In parallel, individuals with key skills may be effectively irreplaceable in the workforce, leading to much more economic damage than in richer countries (78). Workplace-related accidents are also likely to be more common in developing countries where 'the extrusion of drinking from the workplace' (79) is yet to occur, and a variety of harms may be more likely in the absence of a well-developed treatment system for alcohol dependents (assuming such treatment is cost-effective). Finally, and as suggested by the health cost estimate above, the burden of alcohol on human health is greater in developing countries. Coming down definitively on either side of this argument is impossible given the current research base, as it is likely that the net effect involves a balancing of these factors against each other.

There is, however, a further burden that should be considered, although it could never be included as a 'social cost' in the conventional sense - 'reduced economic development' (as the World Health Assembly resolution phrased it). Money spent on alcohol can lead to household impoverishment $(80,81)$ and the diversion of money away from investment in economic development (82); it has also been suggested that the move to more expensive and often international beverages may lead to worsening nutrition in women and children (83). Clearly there are also development benefits from increasing and internationalizing alcohol consumption - for example, in employment, government tax revenues, and technology transfer (84). Yet these can be overstated $(78,85)$, especially considering that modernization of brewing and distilling may lead to a reduction in the number of jobs as productivity increased. And clearly, the economic burdens discussed throughout this paper must also be taken into account.

\section{Conclusions}


Having presented a review and some tentative estimates of the global economic burden due to alcohol, followed by a discussion of the problems in such studies, there remains three final points to be made in this conclusion. The first is to draw attention to the limits of any discussion on the economic burden so-defined, which can only ever quantify a fraction of the true 'cost' of alcohol-related harm. This becomes especially clear when looking at the 'cost savings' from people who die prematurely, which has resulted in a claim by Philip Morris that tobacco deaths in the Czech Republic save the country money (86). Such a morally disastrous conclusion can be avoided by putting a value on pain, suffering and human life itself, although the exact value of these 'intangible costs' will always be contentious. Even so, the various values that have been placed on healthy human life suggest that these intangible costs are between one- and seven-times the value of the 'real money' costs in the EU (see 9). In other words, there is more to health than economic arguments alone. $^{21}$

Second, few of these studies have evaluated the benefits of alcohol. We can get an idea of the likely size of these for health costs, using a study in Switzerland that explicitly compared different methods and alternative scenarios (38). This showed that the health costs were about $30 \%$ lower if health benefits are taken into account relative to a situation of no consumption - but that the net costs relative to light drinking were only $11 \%$ lower than the gross costs relative to no drinking at all (a much more sensible definition of 'the full net social cost'). No studies have quantified other social benefits of alcohol (see 9), although it should be noted that the size of the alcoholic drinks industry is not an estimate

\footnotetext{
${ }^{21}$ As an aside, it should be noted that 'health economics' as a discipline deals substantially with matters other than production losses, such as Quality of Life and leisure time. The difference between public health and economic approaches is therefore merely a matter of whether money is used as a metric that enables otherwise incommensurate areas (work impairment, premature mortality et al) to be combined in analyses. However, 'economics' in popular and policy usage tends to refer to the narrower set of concerns that have here been labelled 'economic arguments' in this article, as seen in e.g. the economic impact assessment for the prospective European Commission Communication on alcohol (RAND Europe, to be published later in 2006). Many thanks to an anonymous reviewer for stressing the need to clarify this point.
} 
of the social benefit of alcohol, as many of the resources employed in making and selling these drinks would be used for other purposes $(17,42,87)$.

Finally, the main thrust of this article has been to show that alcohol exerts a substantial economic burden, and that this burden is likely to apply (to some extent) across the world. This in itself is an important adjunct to the ongoing global debate about acting on alcohol, although it must clearly take a 'back seat' compared to health and welfare justifications for reducing alcohol-related harm. Yet it can only be a first step in economic contributions to policymaking, as further research should quantify the share of costs that can be avoided, the policy investments that should be made to avoid them, and should then monitor how effective the policies have been in reducing costs (88). In this vein, the WHO's CHOICE project (see Chisholm et al, this volume) is an important aid for policymakers - yet this paper also clearly understates the case for acting on alcohol, given that it looks only at health outcomes rather than the full burden outlined here. Further analyses should therefore work towards an elusive goal: a comparative analysis of the full costs and benefits of different policies that work to reduce the harm done by psychoactive substances.

\section{Acknowledgements}

Many thanks to Christine Godfrey for helpful comments at various stages of the work, and to Peter Anderson for support during the Alcohol in Europe project (which provided the foundation for the work in this paper). Thanks also to the anonymous reviewer for helpful comments for this final version of the paper.

\section{Conflict of interest}

I declare that I have no conflict of interest relating to the material presented in this paper. 


\section{References}

1. Suhrcke, M., McKee, M., Sauto Arce, R., Tsolova, S., and Mortensen, J. 2005. The contribution of health to the economy in the European Union. European Communities.

2. Single, E., Robson, L., and Xie, X. 1996. The costs of substance abuse in Canada : a cost estimation study [Full report]. Ottawa, ON: Canadian Centre on Substance Abuse.

3. Midanik, L. T. and Room, R. 2005. "Contributions of Social Science to the Alcohol Field in an Era of Biomedicalization." Social Science and Medicine, 60(5): 1107-16.

4. Peterson, S., Peto, V., Rayner, M., Leal, J., Luengo-Gernandez, R., and Gray, A. 2005. European cardiovascular disease statistics (2005 edition). British Heart Foundation Health Promotion Research Group and Health Economics Research Centre, Department of Public Health, University of Oxford.

5. The ASPECT Consortium. 2004. Tobacco or health in the European Union: past, present and future. European Commission.

6. Eurostat. 2004. Statistical analysis of socio-economic costs of accidents at work in the European Union. Luxembourg: Office for Official Publications of the European Communities, 2004.

7. Gutjahr, E. and G. Gmel. 2001. "The Social Costs of Alcohol Consumption." Pp.133-44 in Mapping the Social Consequences of Alcohol Consumption, H. Klingemann and G. Gmel. Dordecht, the Netherlands: Kluwer Academic Publishers on behalf of WHO-EURO.

8. Andlin-Sobocki, P. and Rehm, J. 2005. "Cost of Addiction in Europe." European Journal of Neurology, 12(S1): 28-33.

9. Anderson, P. and Baumberg, B. 2006. Alcohol in Europe, a report for the European Commission.

10. Collins, D. and Lapsley, H. 1991. Estimating the economic costs of drug abuse in Australia. Canberra: Australian Government Printing Service.

11. WHO. 2004. Global status report on alcohol 2004. Geneva: Department of Mental Health and Substance Abuse, World Health Organization.

12. Robson, L. and Single, E. 1995. Literature review of studies on the economic costs of substance abuse. Ottowa: Canadian Centre for Substance Abuse. 
13. Jarl, J. and Lyttkens, C-H. 2005. The societal burden of alcohol misuse: literature review and cost of alcohol related hospitalisation in Skåne, Sweden - 2003. Nationalekonomiska Institutionen, Ekonomihögskolan vid, Lunds Universitet, Kandidatuppsats 10 poäng.

14. Andlin-Sobocki, P. 2004. "Economic Evidence in Addiction: a Review." European Journal of Health Economics, 5(S1): S5-S12.

15. Brecht, J. G., Poldrugo, F., and Schädlich, P. K. 1996. "Alcoholism: The Cost of Illness in the Federal Republic of Germany." PharmacoEconomics, 10(5): 484-93.

16. Aslam, S., Barham, L., Bramley-Harker, E., Dodgson, J., and Spackman, M. 2003. Alcohol in London: a cost-benefit analysis. London, UK: A Final Report for the Greater London Authority Prepared by NERA.

17. Single, E., Collins, D., Easton, B., Harwood, H., Lapsley, H., Kopp, P., and Wilson, E. 2001. International Guidelines for Estimating the Costs of Substance Abuse. 2 ed. World Health Organization.

18. Koopmanschap, M. A. 1998. "Cost-of-Illness Studies: Useful for Health Policy?" PharmacoEconomics, 14: 143-48.

19. Koopmanschap, M. A., Rutten, F. F. H., van Ineveld, M., and van Roijen, L. 1995. "The Friction Cost Method for Measuring Indirect Costs of Disease." Journal of Health Economics, 14: 171-89.

20. Sundhedsministeriet [Ministry of Health]. 1999. "De samfundsøkonomiske konsekvenser af alkoholforbrug" [The Economic consequences of alcohol consumption" in Denmark]. 2nd edition. Copenhagen, Denmark: Ministry of Health.

21. Rehm, J., Baliunas, S., Brochu, S., Fischer, W., Gnam, W., Patra, J., Popova, S., Sarnocinska-Hart, A., and Taylor, B. 2006. The Social Costs of Substance Abuse in Canada 2002. Canadian Centre on Substance Abuse.

22. Tarricone, R. 2006. "Cost-of-Illness Analysis: What Room in Health Economics?" Health Policy, 77: 51-63.

23. Johannesson, M. and Karlsson, G. 1997. "The Friction Cost Method: A Comment." Journal of Health Economics, 16: 249-55.

24. Birnbaum, H. 2005. "Friction-Cost Method As an Alternative to the Human-Capital Method Is Calculating Indirect Costs." PharmacoEconomics, 23(2): 103-4. 
25. Godfrey, C. and S. Parrott. 2005. "The Extent of the Problem and the Cost to the Employer." Pp.21-31 in Addiction at Work: Tackling Drug Use and Misuse in the Workplace, H. Ghodse.

26. Godfrey, C. 2005. "Economics of Smoke-Free Policies." Going Smoke-free: The medical case for clean air in the home, at work and in public places, Tobacco Advisory Group of the Royal College of Physicians. Royal College of Physicians.

27. Godfrey, C. 1991. "Discussion of "The Social Costs of Drinking"." Expert meeting on the negative social consequences of alcohol use [Oslo, 27-31 August 1990], Norwegian Ministry of Health and Social Affairs. Oslo, Norway.

28. Collins, D. and Lapsley, H. 2002. Counting the cost: estimates of the social costs of drug abuse in Australia in 1998-9. Canberra: Australian Government Printing Service. http://www.health.gov.au/internet/wcms/publishing.nsf/Content/health-pubh/th-publicatmono.htm/\$FILE/mono49.pdf

29. Easton, B. 1997. The social costs of tobacco use and alcohol misuse. Public Health Monograph. 2 ed. Wellington, New Zealand: Department of Public Health, Wellington School of Medicine.

30. Ernst \& Young Netherlands. 2006. The contribution made by beer to the European economy: employment, value added and tax (full report). Amsterdam, Netherlands: Ernst \& Young for the Brewers of Europe.

31. Barker, F. 2002. Consumption externalities and the role of Government: the case of alcohol. Working Paper 02/25. New Zealand Treasury.

32. Heien, D. M. and Pittman, D. J. 1993. "The External Costs of Alcohol Abuse." Journal of Studies on Alcohol, 54: 302-7.

33. Manning, W. G., Keeler, E. B., Newhouse, J. P., Sloss, E. M., and Wasserman, J. 1989. "The Taxes of Sin: Do Smokers and Drinkers Pay Their Way?" Journal of the American Medical Association, 261: 1604-9.

34. McMillan, G. P. and Lapham, S. C. 2004. "Does Moderate Alcohol Use Affect HealthCare Costs? A Propensity Analysis of Female Health-Care Workers." Addiction, 99(5): 612-20. 
35. Anzai, Y., Kuriyama, S., Nishino, Y., Takahashi, K., Ohkubo, T., Ohmori, K., Tsubono, Y., and Tsuji, I. 2005. "Impact of Alcohol Consumption Upon Medical Care Utilization and Costs in Men: 4-Year Observation of National Health Insurance Beneficiaries in Japan." Addiction, 100: 19-27.

36. Rehm, J. 2005. "Selection and Self-Selection: How to Determine the Real Impact of Alcohol on Health-Care Utilization and Costs? [Commentary on Anzai Et Al]." Addiction, 100(1): 28.

37. Bonneux, L., Barendregt, J. J., Nusselder, W. J., and Van der Maas, P. J. 1998. "Preventing Fatal Diseases Increases Healthcare Costs: Cause Elimination Life Table Approach." British Medical Journal, 316: 26-29.

38. Jeanrenaud, C., Priez, F., Pellegrini, S., Chevrou-Severac, H., and Vitale, S. 2003. Le coût social de l'abus d'alcool en Suisse [The social costs of alcohol in Switzerland]. Neuchâtel, Switzerland: Institut de recherches économiques et régionales, Université de Neuchâtel.

39. Meltzer, D. 1997. "Accounting for Future Costs in Medical Cost-Effectiveness Analysis." Journal of Health Economics, 16: 33-64.

40. Rehm, J., R. Room, M. Monteiro, G. Gmel, K. Graham, N. Rehn, C. T. Sempos, U. Frick, and D. Jernigan. 2004. "Alcohol." Comparative quantification of health risks: Global and regional burden of disease due to selected major risk factors, M. Ezzati, A. D. Lopez, A. Rodgers, and C. J. L. Murray. Geneva: WHO.

41. Jones, S., Casswell, S., and Zhang, J-F. 1995. "The Economic Costs of Alcohol-Related Absenteeism and Reduced Productivity Among the Working Population of New Zealand." Addiction, 90(11): 1455-61.

42. Leontaridi, R. 2003. Alcohol misuse: How much does it cost? London: Cabinet Office.

43. Lima, E. and Esquerdo, T. 2003. The economic costs of alcohol misuse in Portugal. Working Paper Series No. 24. Núcleo de Investigação em Microeconomia Aplicada, Universidade do Minho.

44. Nakamura, K., Tanaka, A., and Takano, T. 1993. "The Social Cost of Alcohol Abuse in Japan." Journal of Studies on Alcohol, 54(5): 618-25. 
45. KPMG. 2001. Excessive alcohol consumption in the Netherlands: trends and social costs. Hoofddorp: KPMG Economic Consulting.

46. Harwood, H., Fountain, D., and Livermore, G. 1998. The economic costs of alcohol and drug abuse in the United States - 1992. Report prepared for the National Institute on Drug Abuse (NIDA) and the National Institute on Alcohol Abuse and Alcoholism (NIAAA), National Institutes of Health, Department of Health and Human Services (NIH Publication No. 98-4327). Washington ed. Rockville, MD: National Institutes of Health.

47. Tekin, E. 2004. "Employment, Wages, and Alcohol Consumption in Russia." Southern Economic Journal, 71(2): 397-417.

48. Zarkin, G. A., French, M. T., Mroz, T., and Bray, J. W. 1998. "Alcohol Use and Wages: New Results From the National Household Survey on Drug Abuse." Journal of Health Economics, 17(1): 53-68.

49. Barrett, G. F. 2002. "The Effect of Alcohol Consumption on Earnings." Economic Record, 78(240): 79-96.

50. van Ours, J. C. 2004. "A Pint a Day Raises a Man's Pay; but Smoking Blows That Gain Away." Journal of Health Economics, 23: 863-86.

51. Dave, D. and Kaestner, R. 2002. "Alcohol Taxes and Labor Market Outcomes." Journal of Health Economics, 21: 357-71.

52. Peters, B. L. 2004. "Is There a Wage Bonus From Drinking? Unobserved Heterogeneity Examined." Applied Economics, 36: 2299-315.

53. Cook, P. J. and Moore, M. J. 2002. "The Economics of Alcohol Abuse and AlcoholControl Policies." Health Affairs, 21(2): 120-133.

54. Fernandez-Esquer, M. E. 2003. "Drinking for Wages: Alcohol Use Among Cantineras." Journal of Studies on Alcohol, 64(2): 160-166.

55. Watts, Robert. 26-12-2004. "Advertising is the UK's booziest business." Telegraph.

56. Cook, P. J. 1991. "The Social Costs of Drinking." Expert meeting on the negative social consequences of alcohol use [Oslo, 27-31 August 1990], Norwegian Ministry of Health and Social Affairs. Oslo, Norway. 
57. Salomaa, J. 1995. "The Costs of the Detrimental Effects of Alcohol Abuse Have Grown Faster Than Alcohol Consumption in Finland." Addiction, 90(4): 525-37.

58. Miller, T. R., Lestina, D. C., and Spicer, R. S. 1998. "Crash Costs in the United States by Age, Blood Alcohol Level, Victim Age, and Restraint Use." Accident Analysis and Prevention, 30(2): 137-50.

59. Miller, T. R. and Blewden, M. 2001. "Costs of Alcohol-Related Crashes: New Zealand Estimates and Suggested Measures for Use Internationally." Accident Analysis and Prevention, 33: 783-91.

60. Rice, D. P., Kelman, S., Miller, L. S., and Dunmeyer, S. 1990. The Economic Cost of Alcohol and Drug Abuse and Mental Illness 1985. Report submitted to the Office of Financing and Coverage Policy of the Alcohol, Drug Abuse, and Mental Health Administration. San Francisco: Institute for Health and Aging, University of California. DHHS Publication No. (ADM) 90-1694.

61. Bergmann, E. and Horch, K. 2002. Kosten alkoholassoziierter Krankheiten: Schätzung für Deutschland [The cost of alcohol-related illness: estimates for Germany]. Berlin, Germany: Robert Koch-Institute.

62. Haacker, M. 2006. The Macroeconomics of HIV/AIDS. International Monetary Fund.

63. Krupitsky, E. M., Horton, N. J., Wililams, E. C., Lioznov, D., Kuznetsova, M., Zvartau, E., and Samet, J. H. 2005. "Alcohol Use and HIV Risk Behaviors Among HIV Infected Hospitalized Patients in St. Petersburg, Russia." Drug and Alcohol Dependence, 79(2): 251-56.

64. Madhivanan, P., Hernandez, A., Gogate, A., Stein, E., Gregorich, S., Setia, M., Kumta, S., Ekstrand, M., Mathur, M., Jerajani, H., and Lindan, C. P. 2005. "Alcohol Use by Men Is a Risk Factor for the Acquisition of Sexually Transmitted Infections and Human Immunodeficiency Virus From Female Sex Workers in Mumbai, India." Sexually Transmitted Diseases, 32(11): 685-90.

65. Kaljee, L. M., Genberg, B. L., Minh, T. T., Tho, L. H., Thoa, L. T. K., and Stanton, B. 2005. "Alcohol Use and HIV Risk Behaviors Among Rural Adolescents in Khanh Hoa Province Viet Nam." Health Education Research, 20(1): 71-80. 
66. Lin, D. H., Li, X. M., Yang, H. M., Fang, X. Y., Stanton, B., Chen, X. G., Abbery, A., and Liu, H. J. 2005. "Alcohol Intoxication and Sexual Risk Behaviors Among Rural-to-Urban Migrants in China." Drug and Alcohol Dependence, 79(1): 103-12.

67. Matos, T. D., Robles, R. R., Sahai, H., Colon, H. M., Reyes, J. C., Marrero, C. A., Calderon, J. M., and Shepard, E. W. 2004. "HIV Risk Behaviors and Alcohol Intoxication Among Injection Drug Users in Puerto Rico." Drug and Alcohol Dependence, 76(3): 2292345.

68. Simbayi, L. C., Kalichman, S. C., Jooste, S., Mathirti, V., Cain, D., and Cherry, C. 2004. "Alcohol Use and Sexual Risks for HIV Infection Among Men and Women Receiving Sexually Transmitted Infection Clinic Services in Cape Town, South Africa." Journal of Studies on Alcohol, 65(4): 434-42.

69. Kebede, D., Alem, A., Mitike, G., Enquselassie, F., Berhane, F., Abebe, Y., Ayele, R., Lemma, W., Assefa, T., and Gebremichael, T. 2005. "Khat and Alcohol Use and Risky Sex Behaviour Among in-School and Out-of-School Youth in Ethiopa." BMC Public Health, 5: 109.

70. MacQueen, K. M., Nopkesorn, T., and colleagues. 1996. "Alcohol Consumption, Brothel Attendance and Condom Use: Normative Expectations Among Thai Military Conscripts." Medical Anthropology Quarterly, 10: 402-23.

71. WHO. 2005. Alcohol Use and Sexual Risk Behaviour: A Cross-Cultural Study in Eight Countries. Geneva.: WHO Mental Health: Evidence and Research.

72. Maisto, S. A., Carey, M. P., Carey, K. B., Gordon, C. M., and Schum, J. L. 2004. "Effects of Alcohol and Expectancies on HIV-Related Risk Perception and Behavioral Skills in Heterosexual Women." Experimental and Clinical Psycopharmacology, 12(4): 288-97.

73. Cook, R. L. and Clark, D. B. 2005. "Is There an Association Between Alcohol Consumption and Sexually Transmitted Diseases? A Systematic Review." Sexually Transmitted Diseases, 32(3): 156-64.

74. Grossman, M., Kaestner, R., and Markowitz, S. 2004. An Investigation of the effects of alcohol policies on youth STDs. NBER Working Paper No. 10949.

75. National Institue on Alcohol Abuse and Alcoholism (NIAAA). 2002. "Alcohol and HIV/AIDS." Alcohol Alert, 57. 
76. Leigh, B. C. 2002. "Alcohol and Condom Use: a Meta Analysis of Event-Level Studies." Sexually Transmitted Diseases, 29: 476-82.

77. Morawski, J., J. Moskalewicz, and I. Wald. 1991. "Economic Costs of Alcohol Abuse, With Special Emphasis on Productivity." Expert meeting on the negative social consequences of alcohol use [Oslo, 27-31 August 1990], Norwegian Ministry of Health and Social Affairs. Oslo, Norway.

78. Curry, R. L. 1993. "Beverage Alcohol As a Constraint to Development in the Third World." International Journal of the Addictions, 28: 1227-42.

79. Room, R. and Bullock, S. 2002. "Can Alcohol Expectancies and Attributions Explain Western Europe's North-South Gradient in Alcohol's Role in Violence?" Contemporary Drug Problems, 69(3): 619-48.

80. Saxena, S. 1999. "India." Alcohol and public health in 8 developing countries, WHO/HSC/SAB/99.9 ed. L. Riley and M. Marshall. Substance abuse department, social change and mental health, WHO Geneva.

81. Lightwood, J., D. Collins, H. Lapsley, and T. Novotny. 2000. "Estimating the Costs of Tobacco Use." Tobacco control in developing countries, P. Jha and F. J. Chaloupka. OUP for the World Bank and World Health Organization.

82. Marshall, M. 1999. "Papua New Guinea." Alcohol and public health in 8 developing countries, WHO/HSC/SAB/99.9 ed. L. Riley and M. Marshall. Substance abuse department, social change and mental health, WHO Geneva.

83. Vanesterik, P. and Greer, J. 1985. "Beer Consumption and Third World Nutrition." Food Policy, 10(1): 11-13.

84. World Bank Group. 2000. World Bank Group note on alcohol beverages.

85. Curry, R. L. 1987. "A Framework for National Alcohol Programmes in Developing Countries." British Journal of Addiction, 82: 721-26.

86. BBC News Online. 2001. "Smoking is cost-effective, says report [17 July]." BBC News.

87. Lehto, J. 1995. The economics of alcohol policy. WHO Regional Publications, European Series, No. 61. WHO-EURO. 
88. Collins, D. and Lapsley, H. 2000. Economic evaluation of policies and programmes: further uses of estimates of the social costs of substance abuse. Vienna: United Nations International Drug Control Programme.

89. Collins, D. and Lapsley, H. 1996. The social costs of drug abuse in Australia in 1988 and 1992. Canberra: Australian Government Printing Service.

http://www.health.gov.au/internet/wcms/Publishing.nst/Content/health-pubh/th-publicatdocument-mono30-cnt.htm/\$FILE/mono30.pdf

90. Muizer, A. P., Reinhard, O. P. M., and Rood-Bakker, D. S. 1996. Externaliteiten van alcohol gebruik: naar een doeltreffend alcoholbeleid [Social costs: externalities of alcohol consumption, costs and benefits for third parties]. Rotterdam: Netherlands: Netherlands Economics Institute (NEI) on behalf of the Dutch Foundation for the Responsible Use of Alcohol (STIVA) [see also the Condensed Summary by Muizer and Rood-Bakker in English].

91. Pacolet, J., Degreef, T., and Bouten, R. 2004. Analyse des coûts sociaux et bénéfices en matière de consommation et d'abus d'alcool en Belgique: synthèse [Analysis of the social costs and benefits due to the consumption and abuse of alcohol in Belgium: executive summary].

92. Devlin, N. J., Scuffman, P. A., and Bunt, L. J. 1997. "The Social Cost of Alcohol Abuse in New Zealand." Addiction, 92: 1491-505.

93. Gjelsvik, R. 2004. Utredning av de samfunnsmessige kostnadene relatert til alkohol [Counting the economic costs caused by alcohol]. Norway: Directorate for Health and Social Affairs, the Rokkan Centre, and the Norwegian Institute for Alcohol and Drug Research (SIRUS).

94. Guest, J. and Varney, S. 2001. Alcohol misuse in Scotland: trends and costs. Scottish Executive.

95. Kopp, P. and Fenoglio, P. 2000. Le coût social des drogues licites (alcool et tabac) et illicites en France [The social costs of licit (alcohol and tobacco) and illicit drugs in France]. Étude $\mathrm{n}^{\circ} 22$. Paris, France: Observatoire français des drogues et des toxicomanies.

96. Fenoglio, P., Parel, V., and Kopp, P. 2003. "The Social Cost of Alcohol, Tobacco and Illicit Drugs in France, 1997." European Addiction Research, 9(1): 18-28. 
97. Kozíková, I. E. 1995.

98. Reynaud, M., Gaudin-Colombel, A. F., and Le Pen, C. 2001. "Two Methods of Estimating Health Costs Linked to Alcoholism in France (With a Note on Social Costs)." Alcohol and Alcoholism, 36(1): 89-95.

99. Sesok, J. 2003. Indicators of harmful alcohol drinking in Slovenia in the year 2002 [in Slovenian]. Ljubljana: Institute of Public Health of the Republic of Slovenia.

100. García-Sempere, A. and Portella, E. 2002. "Los Estudios Del Coste Del Alcoholismo: Marco Conceptual, Limitaciones y Resultados En España [Studies of the Cost of Alcoholism: Concepts, Limitations and Results From Spain]." Addicciones, 14(Suplemento 1): 141-53.

101. Byrne, S. 2000. The cost of alcohol-related problems in Ireland. Dublin Institute of Technology.

102. Johnson, A. 2000. Hur mycket kostar supen? [How much for the booze?]. Stockholm: Sober.

103. Collicelli, C. 1996. "Income From Alcohol and the Costs of Alcoholism: an Italian Experience." Alcologia, 8(2): 135-43.

104. Harwood, H., Fountain, D., and Livermore, G. 1999. "Cost Estimates for Alcohol and Drug Abuse." Addiction, 94(5): 631-34.

105. Baltic Data House. 2001. Economic research about the influence of taxes imposed on alcohol and influence of price policy on alcohol consumption; research about accidents caused by alcohol intoxication. Riga, LV: Market and Social Research Group, Baltic Data House, Baltic Institute of Social Sciences.

106. Godfrey, C. 2004. The Financial Costs and Benefits of Alcohol

107. Maynard, A., Godfrey, C., and Hardman, G. 1994. Conceptual Issues in Estimating the Social Costs of Alcohol 11-5-1994),

108. Bray, J. W. 2005. "Alcohol Use, Human Capital, and Wages." Journal of Labor Economics, 23(2): 279-312.

109. Hensing, G. and Wahlstrom, R. 2004. "Chapter 7. Sickness Absence and Psychiatric Disorders." Scandinavian Journal of Public Health, 32(Suppl 63): 152-80. 
Page 31 of 38 
Table 1 - Overall comparison of social cost studies included in the review

\begin{tabular}{|c|c|c|c|c|c|c|c|}
\hline & 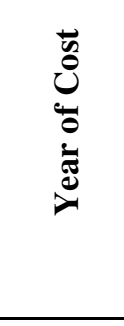 & 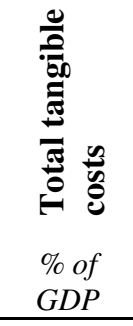 & 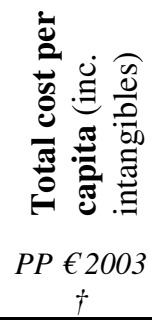 & & 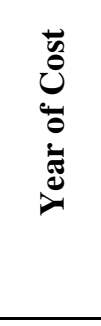 & 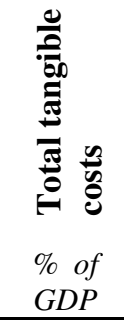 & 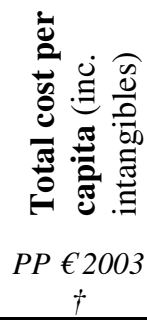 \\
\hline Australia $(28,89)$ & $1998 / 9$ & $0.9-1.0$ & $286-315$ & * N'lands (90) & 1996 & 0.3 & 78 \\
\hline * Belgium (91) & 1999 & 2.4 & 586 & New Zealand (29) & 1990 & 4.7 & 4289 \\
\hline Canada (2) & 1992 & $0.9-1.3$ & $195-265$ & New Zealand (92) & 1991 & $1.4-2.4$ & $234-386$ \\
\hline Canada (21) & 2002 & $0.7-1.7$ & $180-451$ & $\Varangle N e w$ Zealand(59) & 1996 & - & - \\
\hline Denmark & 1996 & 0.9 & 218 & Norway (93) & 2001 & $1.2-2.1$ & $447-729$ \\
\hline Eng. \& Wales (42) & 2001 & $1.5-1.7$ & $456-497$ & Portugal (43) & 1995 & 0.5 & 73 \\
\hline Finland (57) & 1990 & $1.3-1.8$ & $482-823$ & Scotland (94) & $2001 /$ & 0.7 & $296-360$ \\
\hline France $(95,96)$ & 1997 & $1.2-1.4$ & $256-300$ & Slovak R. (97) & 1994 & 3.1 & 292 \\
\hline France (98) & 1996 & - & - & Slovenia (99) & 2002 & 0.3 & 50 \\
\hline Germany (61) & 1995 & 1.1 & 253 & Spain (100) & 1998 & 0.7 & 129 \\
\hline Ireland (101) & 2003 & 1.6 & 447 & Sweden (102) & 1998 & 5.5 & 1,194 \\
\hline Italy (103) & 1994 & $0.7-0.8$ & $134-153$ & Switzerland (38) & 1998 & $0.5-0.7$ & $435-482$ \\
\hline Japan (44) & 1993 & 1.9 & 381 & USA $(46,104)$ & 1992 & 2.3 & $666-731$ \\
\hline Latvia (105) & 1999 & 1.8 & 113 & USA (60) & 1985 & 1.7 & 447 \\
\hline N'lands (45) & 2000 & 0.7 & 171 & $\neq U S A$ & 1995 & - & - \\
\hline
\end{tabular}

Figures may differ from reported headline figures as ranges may be taken from sensitivity analyse; * = Industry-funded study; $\dagger=$ Total cost is inflated to 2003 prices and adjusted for purchasing power; $\neq=$ DUI costs only 
Table 2 - Review of health costs (selection of most methodologically sound studies)

\begin{tabular}{|c|c|c|c|c|}
\hline & 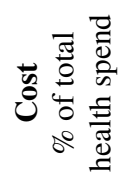 & 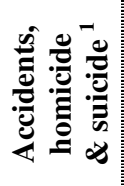 & $\sum \frac{\pi}{2}$ & 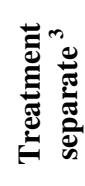 \\
\hline Canada (2) & 1.3-1.6 & $\mathbf{Y}$ & $\mathbf{Y}$ & $\mathbf{Y}$ \\
\hline Canada (21) & 2.3 & $\mathbf{Y}$ & $\mathbf{Y}$ & $\mathbf{Y}$ \\
\hline Denmark & 3.4 & & $\mathrm{Y}$ & \\
\hline England \& Wales (27) & $2.8-3.3$ & $\mathbf{Y}$ & $\mathbf{Y}$ & $\mathbf{Y}$ \\
\hline Finland (29) & $0.9-1.4$ & $\mathrm{Y}$ & & $\mathrm{Y}$ \\
\hline France $(31,32)$ & 2.4 & & $\mathrm{Y}$ & \\
\hline Germany (36) & 2.3 & $\mathbf{Y}$ & $\mathbf{Y}$ & $\mathbf{Y}$ \\
\hline Italy (40) & $1.7-1.9$ & & & $\mathrm{Y}$ \\
\hline Japan (42) & 4.9 & & & \\
\hline Latvia (105) & & $\mathbf{Y}$ & & \\
\hline Netherlands (46) & 0.3 & & & $\mathrm{Y}$ \\
\hline * Netherlands (21) & 0.7 & & & $\mathrm{Y}$ \\
\hline New Zealand (24) & 1.3 & $\mathbf{Y}$ & $\mathbf{Y}$ & \\
\hline Norway (26) & $0.7-1.3$ & & $\mathrm{Y}$ & $\mathrm{Y}$ \\
\hline Portugal (28) & 0.5 & & & $\mathrm{Y}$ \\
\hline Scotland (30) & 1.4 & & $\mathrm{Y}$ & $\mathrm{Y}$ \\
\hline Spain (37) & 2.4 & & & $\mathrm{Y}$ \\
\hline Switzerland (41) & 1.4 & $\mathbf{Y}$ & $\mathbf{Y}$ & $\mathbf{Y}$ \\
\hline USA $(4,43)$ & 1.5 & $\mathbf{Y}$ & $\mathbf{Y}$ & $\mathbf{Y}$ \\
\hline
\end{tabular}

\footnotetext{
${ }^{1}$ Indicates whether studies included accidents, homicide and suicide (studies omitting these will produce noticeably lower results).

2 'AAF method' = use of the Alcohol Attributable Fraction (AAF) method (17), where international epidemiological evidence on relative risk is combined with national surveys on prevalence. Those studies not using this method either restrict themselves to conditions defined as attributable to alcohol, or are little more than 'guesstimates'.

3 'Treatment separate' indicates whether the study values specialist addiction treatment separately to the main figure. Often it is unclear whether these costs are incorporated within the headline health cost, or whether there was insufficient data to evaluate these.
} 
Table 3 - Review of premature mortality costs using the human capital method

\begin{tabular}{|c|c|c|c|c|c|c|}
\hline & \multicolumn{2}{|c|}{$\begin{array}{l}\text { Cost }(\% o \text { (per } \\
\text { thousand) of GDP }\end{array}$} & \multicolumn{4}{|c|}{ Details of method } \\
\hline & 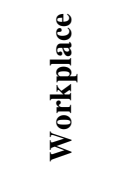 & $\frac{\frac{8}{\tilde{z}}}{\dot{z}}$ & 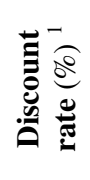 & 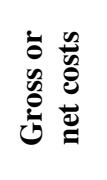 & 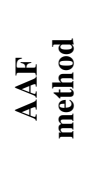 & 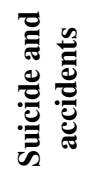 \\
\hline \multirow{3}{*}{ Canada (2) } & \multicolumn{2}{|c|}{$2.4-2.6$} & 10 & Gross & $\mathrm{Y}$ & $\mathrm{Y}$ \\
\hline & \multicolumn{2}{|c|}{3.9} & 6 & Gross & $\mathbf{Y}$ & $\mathbf{Y}$ \\
\hline & \multicolumn{2}{|c|}{5.4} & 4 & Gross & $\mathbf{Y}$ & $\mathbf{Y}$ \\
\hline Canada (21) & \multicolumn{2}{|c|}{1.6} & 5 & Gross & $\mathbf{Y}$ & $\mathbf{Y}$ \\
\hline Denmark (20) & 1.7 & - & 3.25 & Gross & $\mathrm{Y}$ & $\mathrm{Y}$ \\
\hline $\begin{array}{l}\text { England \& Wales } \\
\text { (Leontaridi) }\end{array}$ & $2.6-2.8$ & - & $3.5^{*}$ & Gross & $\mathrm{Y}$ & $\mathrm{Y}$ \\
\hline \multirow{2}{*}{ Finland (57) } & 6.5 & - & 10 & Gross & & $\mathrm{Y}$ \\
\hline & 10.3 & - & 4 & Gross & & $\mathrm{Y}$ \\
\hline France (96) & 4.4-6.5 & - & 6 & Gross & $\mathbf{Y}$ & $\mathbf{Y}$ \\
\hline Germany (61) & 3.7 & 0.2 & 2 & Gross & $\mathrm{Y}$ & $\mathrm{Y}$ \\
\hline \multirow{2}{*}{ New Zealand (92) } & 0.3 & - & 10 & Gross & $\mathrm{Y}$ & $\mathrm{Y}$ \\
\hline & 0.6 & - & 5 & Gross & $\mathrm{Y}$ & $\mathrm{Y}$ \\
\hline Norway (93) & $1.6-9.3$ & - & $3.5^{*}$ & Gross & $\mathrm{Y}$ & \\
\hline \multirow{3}{*}{ Switzerland (38) } & 1.4 & 0.8 & 6 & Net & $\mathrm{Y}$ & $\mathrm{Y}$ \\
\hline & 2.0 & 1.2 & 2 & Net & $\mathrm{Y}$ & $\mathrm{Y}$ \\
\hline & 2.6 & 1.6 & 0 & Net & $\mathrm{Y}$ & $\mathrm{Y}$ \\
\hline \multirow{3}{*}{$U S(46)$} & \multicolumn{2}{|c|}{4.9} & 6 & Gross & $\mathbf{Y}$ & $\mathbf{Y}$ \\
\hline & \multicolumn{2}{|c|}{6.3} & 5 & Gross & $\mathbf{Y}$ & $\mathbf{Y}$ \\
\hline & \multicolumn{2}{|c|}{7.2} & 3 & Gross & $\mathrm{Y}$ & $\mathrm{Y}$ \\
\hline
\end{tabular}

\footnotetext{
${ }^{1}$ The discount rate is a way of turning future costs into present-day values (as the same amount of money is more valuable now than in 10 years). The WHO's Guidelines (17) suggested that all studies should include estimates using rates of 5\% and $10 \%$ to aid comparison; only studies with rates of 4-6\% are highlighted in bold to aid comparison.
}

* Reduced to $3 \%$ after 30 years. 
Table 4 - Review of absenteeism costs

\begin{tabular}{|c|c|c|c|}
\hline & 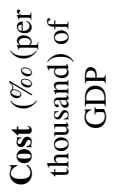 & to & 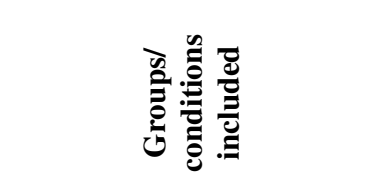 \\
\hline Australia & 0.1 & Hospitalization & $\begin{array}{l}\text { See discussion of method in } \\
\text { text (demographic model) }\end{array}$ \\
\hline \multirow[b]{2}{*}{ England \& Wales (27) } & 1.4 & \multirow[b]{2}{*}{ Employee survey } & Alcohol dependents \\
\hline & 2.0 & & $\begin{array}{l}\text { All drinkers (injury only) } \\
\text { and alcohol dependents }\end{array}$ \\
\hline France $(31,32)$ & $0.4-0.5$ & Hospitalization & $\begin{array}{c}\text { Excludes accidents and } \\
\text { suicide (see Table 2) }\end{array}$ \\
\hline Germany (36) & 0.8 & Hospitalization \& treatment & $\begin{array}{l}\text { Long-term absences directly } \\
\text { attributable to alcohol, plus } \\
\text { occupational disability }\end{array}$ \\
\hline Italy (40) & $1.7-1.8$ & Hospitalization & $\begin{array}{l}\text { 'Alcoholics' plus all in } \\
\text { alcohol-related accidents }\end{array}$ \\
\hline Japan (42) & 0.1 & Hospitalization \& treatment & No further detail \\
\hline New Zealand (92) & 0.2 & Hospitalization & $\begin{array}{l}\text { Assumes alcohol abusers } \\
\text { will be } 25 \% \text { less efficient } \\
\text { than general population }\end{array}$ \\
\hline Norway (26) & $1.0-1.1$ & Employee survey & No further detail \\
\hline Slovenia & 0.1 & Hospitalization & No further detail \\
\hline
\end{tabular}

1 'Hospitalization' refers to estimates based on the number of days spent in hospital for alcohol-attributable conditions as a lower bound for the total alcohol-attributable absenteeism. 'Employee survey' refers to primary research on how levels of absenteeism link to alcohol use disorders in the individual. 
Table 5 - Review of unemployment costs (all transparent studies)

\begin{tabular}{|c|c|c|c|}
\hline & 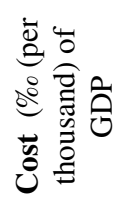 & 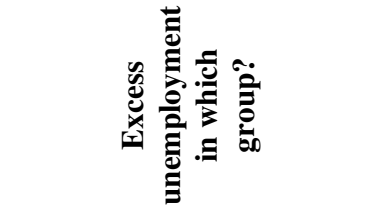 & 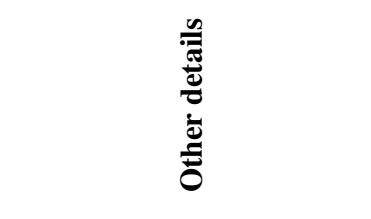 \\
\hline \multirow{2}{*}{ England \& Wales (27) } & 2.0 & $\begin{array}{l}\text { Alcohol abusers and alcohol } \\
\text { dependents - men only }\end{array}$ & \multirow{2}{*}{$\begin{array}{l}\text { Based on MacDonald and } \\
\text { Shields (2004 }\end{array}$} \\
\hline & 2.4 & $\begin{array}{l}\text { Alcohol abusers and alcohol } \\
\text { dependents - both genders }\end{array}$ & \\
\hline Netherlands (45) & 2.4 & 'Problem drinkers' & $\begin{array}{l}\text { Assumes } 1 / 2 \text { of this is due to } \\
\text { confounding }\end{array}$ \\
\hline Norway (93) & 0.6 & $\begin{array}{l}\text { Those suffering from } \\
\text { alcohol use disorders }\end{array}$ & $\begin{array}{c}\text { Based on MacDonald and } \\
\text { Shields (2004) }\end{array}$ \\
\hline Scotland (94) & 1.3 & Alcohol dependents & $\begin{array}{c}\text { Uses national data on } \\
\text { employment rates in alcohol } \\
\text { dependents v. others }\end{array}$ \\
\hline Switzerland (38) & 0.6 & $\begin{array}{l}\text { Heavy alcohol users }(>4 \\
\text { glasses/day f, }>6 \text { glass m) }\end{array}$ & \\
\hline USA (46) & $0.0^{1}$ & $\begin{array}{l}\text { Alcohol abusers and alcohol } \\
\text { dependents }\end{array}$ & $\begin{array}{c}\text { Multivariate regression } \\
\text { analysis }\end{array}$ \\
\hline
\end{tabular}

\footnotetext{
${ }^{1}$ Harwood et al did attempt to estimate the effect of alcohol use disorders on unemployment, but found no influence of any of their alcohol measures on any of their employment measures.
} 
Table 6 - Review of crime costs

\begin{tabular}{|c|c|c|c|c|c|c|}
\hline & 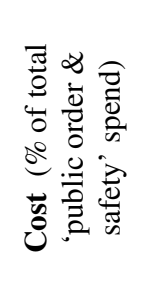 & 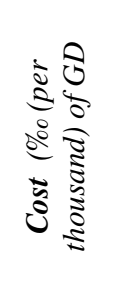 & 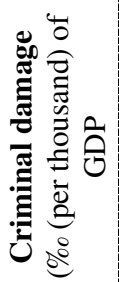 & 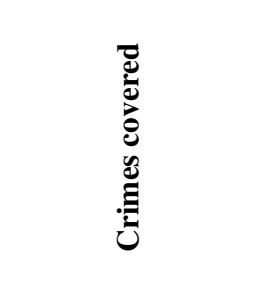 & 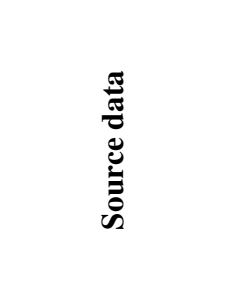 & 总 \\
\hline Australia & $8.4-15.9$ & $1.4-2.7$ & - & All & $\begin{array}{c}\text { Arrestee and } \\
\text { prisoner surveys }\end{array}$ & $\begin{array}{c}\text { Arrestee/prisoner } \\
\text { attributions }\end{array}$ \\
\hline Belgium (91) & 1.4 & 0.2 & - & $*$ & $*$ & $*$ \\
\hline Canada (2) & $10.5-12.3$ & $1.9-2.3$ & - & \multirow{2}{*}{$\begin{array}{c}\text { Violence and } \\
\text { property offences, } \\
\text { alcohol-defined } \\
\text { crime }\end{array}$} & $?$ & $?$ \\
\hline Canada (21) & 14.4 & 2.7 & - & & $\begin{array}{c}\text { Arrestee and } \\
\text { prisoner surveys }\end{array}$ & $\begin{array}{c}\text { Arrestee/prisoner } \\
\text { attributions }\end{array}$ \\
\hline $\begin{array}{l}\text { England \& Wales } \\
(27)\end{array}$ & 10.6 & 2.1 & 1.6 & All & $\begin{array}{l}\text { Victim surveys, } \\
\text { supplemented by } \\
\text { arrestee research }\end{array}$ & None \\
\hline Finland (29) & $12.7-13.9$ & $1.7-1.9$ & 0.6 & All & Unclear & Unclear \\
\hline Netherlands (46) & 1.4 & 0.2 & 0.7 & $*$ & $*$ & $*$ \\
\hline * Netherlands (21) & 3.7 & 0.2 & 0.7 & $*$ & $*$ & $*$ \\
\hline New Zealand (24) & $\begin{array}{c}25.0- \\
51.6 \\
\end{array}$ & $3.2-6.5$ & - & All & Brown (1986) & Unclear \\
\hline Norway (26) & 1.9 & 0.2 & - & All & Unclear & None \\
\hline Scotland (30) & 14.4 & 3.0 & - & All & $\begin{array}{l}\text { Flat rate for all } \\
\text { offences from } \\
\text { arrestee survey }\end{array}$ & None \\
\hline USA (60) & 9.2 & 0.9 & 0.4 & \multirow{2}{*}{$\begin{array}{c}\text { Violence and } \\
\text { property offences, } \\
\text { alcohol-defined } \\
\text { crime }\end{array}$} & $\begin{array}{c}\text { Harwood et al } \\
(1984)\end{array}$ & $\begin{array}{c}\text { Interviews with } \\
\text { prisoners }\end{array}$ \\
\hline USA $(4,43)$ & 6.4 & 1.0 & - & & $\begin{array}{c}\text { Update of } \\
\text { Harwood et al } \\
(1984)\end{array}$ & $\begin{array}{l}\text { Interviews with } \\
\text { prisoners }\end{array}$ \\
\hline
\end{tabular}

* These three estimates are based on a single source (90), which appears to produce implausible estimates when compared to other research in the Netherlands (see discussion in 9).

${ }^{1}$ Some studies reduce the figure of association between alcohol and crime by e.g. asking prisoners whether they feel they committed a crime because they were drunk (see discussion in 9). 
Table 7 - Review of drink-driving costs ${ }^{1}$

\begin{tabular}{|c|c|}
\hline & 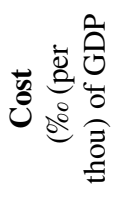 \\
\hline Australia & 1.2 \\
\hline Belgium & 6.2 \\
\hline Canada (2) & 0.7 \\
\hline Canada (21) & 0.7 \\
\hline Denmark & 1.2 \\
\hline France $(31,32)$ & $1.4-2.1$ \\
\hline Germany (36) & 0.4 \\
\hline Japan (42) & $<0.1$ \\
\hline Latvia (105) & 1.7 \\
\hline New Zealand (59) & 1.7 \\
\hline Norway (26) & $<0.1$ \\
\hline Portugal (28) & 0.7 \\
\hline Switzerland (41) & 0.3 \\
\hline USA (60) & 0.6 \\
\hline USA (58) & 1.0 \\
\hline USA $(4,43)$ & 1.2 \\
\hline
\end{tabular}

${ }^{1}$ Studies typically referred to other cost estimates for all road-traffic accidents, of which a proportion was attributed to alcohol. Given that this made detailed methodological comparison problematic, only the two studies (both conducted by the same lead author) that focused entirely on drink-driving (and are also the most transparent and sophisticated) are highlighted in bold. 